\title{
Recovery, Rehabilitation, and Return to Full Duty in a Military Population After a Recent Injury: Differences Between Lower-Extremity and Spine Injuries
}

\author{
Daniel I. Rhon, P.T., D.Sc., Ph.D., Deydre S. Teyhen, P.T., Ph.D., Kyle Kiesel, P.T., Ph.D., \\ Scott W. Shaffer, P.T., Ph.D., Stephen L. Goffar, P.T., Ph.D., Tina A. Greenlee, Ph.D., and \\ Phillip J. Plisky, P.T., D.Sc.
}

\begin{abstract}
Purpose: To compare readiness to return to duty in soldiers following recent lower-extremity versus spine injury. The secondary purposes were to provide normative data for the Selective Functional Movement Assessment Top Tier movements (SFMA-TTM) and assess the association between SFMA-TTM scores and future injury occurrence, comparing injuries of the lower extremity and thoracic/lumbar spine. Methods: SFMA was rated by trained assessors on 480 U.S. Army soldiers within 2 weeks of being cleared to return to duty after recent lower-extremity or lumbar/thoracic injury. Participants were followed for 1 year to determine incidence of subsequent time-loss injury. Results: Only $74.4 \%$ of soldiers felt $100 \%$ mission capable when returning to full duty $(73.6 \%$ lower-extremity; $76.5 \%$ spine). After 1 year, $37.9 \%$ had sustained a time-loss injury, and pain with movement at baseline was associated with higher odds for having an injury (odd ratio $1.5395 \%$ confidence interval 1.04-2.24; $P=.032$ ). Almost all $(99.8 \%)$ had at least 1 dysfunctional pattern, and $44.1 \%$ had pain with at least 1 movement $(40.3 \%$ with previous lower-extremity injury; $54.6 \%$ with previous spine injury) after being cleared to return to duty. Conclusions: One in four patients did not feel $100 \%$ mission capable upon being cleared for full duty. Pain with movement was also associated with future injury. Regardless of recent injury type, $99.8 \%$ of soldiers returned to full unrestricted duty with at least ldysfunctional movement pattern and $44.1 \%$ had pain with at least 1 of the SFMA-TTM movements. Level of Evidence: Level III, retrospective comparative cohort study.
\end{abstract}

$\mathbf{M}$ usculoskeletal injuries are a detriment to military readiness and the primary cause of limited or missed duty days every year. ${ }^{1}$ Consider that $54 \%$ of active-duty service members sustained a new injury in $2019,{ }^{2}$ and in $2017,26 \%$ of active duty soldiers missed

From the Department of Rehabilitation Medicine, Brooke Army Medical Center, San Antonio, Texas (D.I.R., T.A.G.); Department of Rehabilitation Medicine, The Uniformed Services University of the Health Sciences, Bethesda, Maryland (D.I.R.); Office of the Surgeon General, Army Medical Command, Falls Church, Virginia (D.S.T.); Doctoral of Physical Therapy Program, University of Evansville, Indiana (K.K., P.J.P.); and University of the Incarnate Word, School of Physical Therapy, San Antonio, Texas (S.W.S., S.L.G.), U.S.A.

The authors report the following potential conflicts of interest or sources of funding: D.I.R. reports grants from the Department of Defense (Military Operational Medicine Research Program) during the conduct of the study. K.K. and P.J.P. report other from Functional Movement Systems, outside the submitted work. This research was supported by the Department of Defense Military Operational Medicine Research Program under program number W81XWH-13-MOMJPC5-IPPEHA (Award W81XWH-14-2-0141). The view $(s)$ expressed herein are those of the author(s) and do not reflect the official at least 1 day of duty due to a musculoskeletal injury. ${ }^{3}$ Cumulatively, 10,722,742 days were limited in 2017 because of musculoskeletal injuries in the Army alone. ${ }^{3}$ This equates to a staggering 29,377 person-work-years that were lost in productivity that year alone,

policy or position of Brooke Army Medical Center, the U.S. Army Medical Department, the U.S. Army Office of the Surgeon General, the Department of the Army, the Uniformed Services University of Health Sciences, the Department of Defense, or the U.S. Government. Full ICMJE author disclosure forms are available for this article online, as supplementary material.

Received August 2, 2021; accepted September 25, 2021.

Address correspondence to Daniel I. Rhon, P.T., D.Sc., Ph.D., Primary Care Musculoskeletal Research, Department of Rehabilitation Medicine, Brooke Army Medical Center, 3551 Roger Brooke Dr., JBSA Fort Sam Houston, TX 78234.E-mail: daniel.i.rhon.ctr@mail.mil

Published by Elsevier Inc. on behalf of the Arthroscopy Association of North America. This is an open access article under the CC BY-NC-ND license (http://creativecommons.org/licenses/by-nc-nd/4.0/).

2666-061X/211104

https://doi.org/10.1016/j.asmr.2021.09.028 


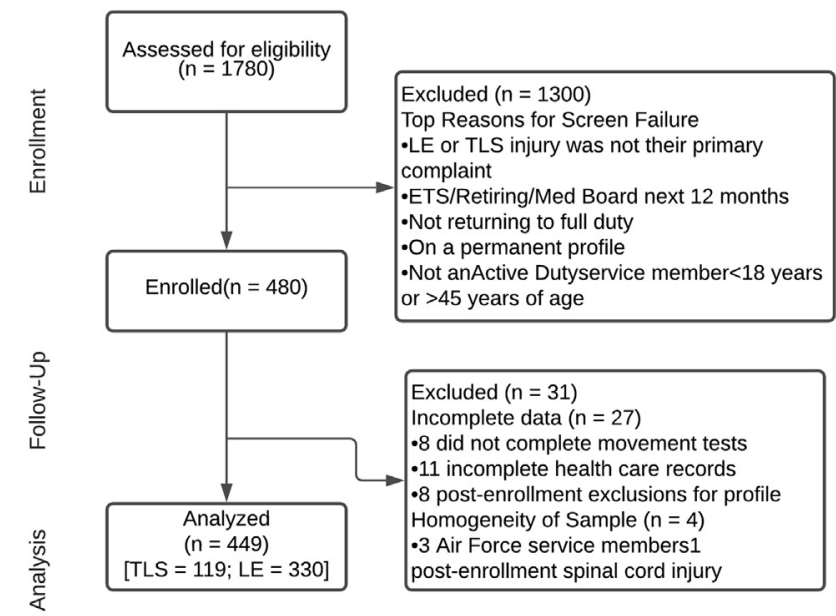

Fig 1. Flow of cohort through study. (ETS, expiration of time of service; LE, lower extremity; TLS, time loss injury.)

affecting training, readiness, the overall ability to complete the military mission, and national security. Returning military tactical athletes to duty after injury quickly and efficiently is one of the top priorities of the Department of Defense. ${ }^{4}$

Similar to collegiate and professional athletes, efficiency is a critical component of returning individuals back to activity and work. The longer the period of time missed from military duty, the greater the impact on the individual and unit mission. However, returning too early, before the individual is ready, can lead to risk for yet another injury, compounding the burden on the individual and military units. ${ }^{1}$ Previous injury is one of the strongest predictors for future injury, ${ }^{5-7}$ placing the individuals with whom clinicians interact at an alreadygreater risk for injury than noninjured counterparts. Deciding when exactly a patient is ready to return to duty with the least risk of sustaining a follow-on injury is one of the most important questions that sports and rehabilitation clinicians face.

For individuals with high physical demands, limitations in the ability to move their body could lead to greater risk of injury. ${ }^{6,8,9}$ Rigorous physical activities can subject a person to large forces, and someone with a healthy neuromusculoskeletal system is better equipped to absorb and redistribute those forces. This is supported by the large body of evidence showing the association between how someone is able to absorb landing forces and risk of injury through various types of hop-testing. ${ }^{10}$ One method that has been developed to assess how well an athlete moves, and in particular side-to-side asymmetry, is the Selective Functional Movement Assessment Top Tier movements (SFMATTM). ${ }^{11}$ As opposed to tools like the Functional Movement Screen, which is designed for use with healthy individuals, the SFMA-TTM was designed for use in clinical settings, to create a clinical framework for systematically identifying and addressing impairments related to painful and dysfunctional movement patterns. ${ }^{12}$ The SFMA-TTM provides an objective score of joint mobility, asymmetry, balance/control, and pain, using 10 movement patterns throughout the entire body, assessing extremity, trunk, and spinal movement. It has high inter- and intrarater reliability. ${ }^{11,13,14}$ Pain relief and regaining function are 2 of 3 primary outcome-related effects that patients report they desire and expect from physical therapy treatment. ${ }^{15}$

In theory, movement impairments should be minimal in individuals returning to sport and activity, to maximize performance and minimize the risk of future injury. Normative data for performance on the SFMA-TTM and the proportion of individuals that still have pain or dysfunctional movement after being cleared to return to sport/activity after an injury do not exist at this time. The primary purpose was to compare readiness to return to duty in Soldiers following recent lower extremity versus spine injury. The secondary purposes were to provide normative data for the SFMA-TTM and assess the association between SFMA-TTM scores and future injury occurrence, comparing injuries of the lower extremity and thoracic/lumbar spine.

\section{Methods}

\section{Study Design}

This was an observational cohort study. Ethics approval was obtained through the institutional review board at Madigan Army Medical Center, Tacoma, WA. All participants provided signed informed consent before participation.

\section{Subjects}

We enrolled soldiers seen consecutively at 3 large military hospitals (Womack Army Medical Center, Beaumont Army Medical Center, and Brooke Army Medical Center) between February 2016 and September 2017. Individuals were included if they were between the ages of 18 to 45 years and returning to unrestricted duty after a complete course of medical care (including physical rehabilitation) for a thoracolumbar spine or lower-extremity injury. Clearance to return to unrestricted military duty was determined by the managing clinician, most often a physical therapist in this setting. We excluded individuals with planned separation from military service in the following 12 months, pregnant (can influence injury risk), adults older than the age of 45 years (to best capture age range of most service members), who had sustained injuries that resulted in an extremity amputation, and anyone pending a medical evaluation board for service-connected disability and separation. 
Table 1. Baseline Descriptive and Demographic Variables of Cohort $(n=449)$

\begin{tabular}{|c|c|c|c|c|}
\hline & All & Lumbar/Thoracic Spine & Lower Extremity & $P$ Value \\
\hline Female sex, n (\%) & $65(14.5)$ & $18(15.1)$ & $47(14.2)$ & .879 \\
\hline Mean age, $y \pm S D(95 \% \mathrm{CI})$ & $27.2 \pm 6.2(26.7-27.8)$ & $27.6 \pm 6.2(26.5-28.8)$ & $27.1 \pm 6.2(26.4-27.8)$ & .419 \\
\hline Mean height, $\mathrm{m} \pm \mathrm{SD}(95 \% \mathrm{CI})$ & $1.7 \pm 0.1(1.7-1.8)$ & $1.7 \pm 0.1(1.7-1.8)$ & $1.7 \pm 0.1(1.7-1.8)$ & .520 \\
\hline Socioeconomic status, n (\%) & & & & .191 \\
\hline Enlisted & $394(87.8)$ & $100(84.0)$ & $294(89.1)$ & \\
\hline Officer/Warrant Officer & $55(12.2)$ & $19(16.0)$ & $36(10.9)$ & \\
\hline At least 1 year but less than 3 years & $104(23.2)$ & $25(21.0)$ & $79(23.9)$ & \\
\hline At least 3 years but less than 5 years & $76(16.9)$ & $23(19.3)$ & $53(16.1)$ & \\
\hline 5 years or more & $103(22.9)$ & $33(27.7)$ & $70(21.2)$ & \\
\hline \multicolumn{5}{|l|}{ Smoking } \\
\hline $\begin{array}{l}\text { Smoked at least } 100 \text { cigarettes in } \\
\text { their lifetime, } \mathrm{n}(\%)\end{array}$ & $145(32.3)$ & $49(41.2)$ & $96(29.1)$ & .017 \\
\hline
\end{tabular}

\section{Procedures}

Performance on the SFMA-TTM was rated by trained assessors and recorded for all participants within 2 weeks of being cleared to return to unrestricted full duty. The SFMA-TTM was completed as part of a battery of tests and measures for a multisite study aimed at the development of return-to-duty standards in the military. ${ }^{16}$ Assessors were licensed physical therapists and fitness professionals who participated in a l-day training session at all sites, graded at the end of the day on their individual performance of each test, to include the SFMA-TTM. These clinicians were also provided a printed copy of the Manual of Operating Procedures that outlined every step of the SFMA-TTM along with scoring criteria for review as needed (all published in the study protocol). ${ }^{16}$

\section{Measures}

Selective Functional Movement Assessment Top-Tier Movement (SFMA-TTM)

The SFMA-TTM involves performance of 10 movement patterns, once each, without warm-up, in a slow and controlled manner following a demonstration and with some basic verbal cuing (details of each movement pattern in appendix of published protocol ${ }^{16}$ ). These movements include Active Cervical Flexion, Active Cervical Extension, Cervical Rotation, Upper Extremity Medial Rotation $\&$ Extension, Upper Extremity Lateral Rotation $\&$ Flexion, Multisegmental Flexion (forward bending), Multisegmental Extension (back bending), Multisegmental (trunk) Rotation, Single Leg Stance, and the Overhead Deep Squat. The SFMA-TTM is scored by combining 2 dichotomies including report of pain with the movement pattern, (yes/no) and movement quality criteria (functional/dysfunctional). When movement function is combined with movement pain, each movement of the SFMA-TTM is rated within 1 of 4 categories: (1) Functional/Nonpainful, (2) Functional/ Painful, (3) Dysfunctional/Painful, and (4) Dysfunctional/Nonpainful. At the beginning of each testing session, subjects were asked to alert the rater if they had any pain with any of the subsequent movements. They were not repeatedly asked after each movement unless there were visual signs of pain. All movements were performed without shoes and socks. The SFMA-TTM has been assessed in military populations, ${ }^{14,17}$ is used in some military clinics, and was found to have acceptable agreement and reliability between raters. ${ }^{11,13,14}$

\section{Time Loss Injury}

When soldiers are diagnosed with an injury that requires an alteration of duty requirements to allow for proper recovery (i.e., no running, no jumping, no marching, etc.), a document termed a "profile" is generated through an electronic database (e-profile in the Medical Operational Data Surveillance System). The diagnosis and specific limitations are demarcated on this document, along with specific limitations. This document is tracked by military commanders for soldiers in their respective units. These data were collected from the e-profile database for every participant for the full year after enrollment into the study; elements that included the number of unique profiles, total days on limited duty, and the associated injury. For this study, we dichotomized participants into having or not having at least 1 time-loss day from an injury during this 1 year follow-up period. Because we included only individuals cleared for duty after a recent lower-extremity or thoracic/lumbar spine injury, we also classified subsequent injuries into either a (1) lower extremity, (2) thoracic/lumbar spine, or (3) other musculoskeletal injury. 
Table 2. Normative Values for Performance on the Selective Functional Movement Assessment (SFMA) after Clearance to Return to Full Unrestricted Duty Following Musculoskeletal Injury $(\mathrm{n}=449)$

\begin{tabular}{|c|c|c|c|c|c|c|c|c|c|c|c|c|}
\hline \multirow[b]{2}{*}{ SFMA Movements } & \multicolumn{4}{|c|}{ All } & \multicolumn{4}{|c|}{ Lumbar/Thoracic Spine } & \multicolumn{4}{|c|}{ Lower Extremity } \\
\hline & FNP & $\mathrm{FP}$ & DP & DNP & FNP & FP & $\mathrm{DP}$ & DNP & FNP & FP & DP & DNP \\
\hline Back bending & $85(18.9)$ & $5(1.1)$ & $120(26.7)$ & $239(53.2)$ & $15(12.6)$ & 0 & $46(38.7)$ & $58(48.7)$ & $70(21.2)$ & $5(1.5)$ & $74(22.4)$ & $181(54.8)$ \\
\hline Cervical extension & $198(44.1)$ & $9(2.0)$ & $33(7.3)$ & $209(46.5)$ & $52(43.7)$ & $2(1.7)$ & $12(10.1)$ & $53(44.5)$ & $146(44.2)$ & $7(2.1)$ & $21(6.4)$ & $156(47.3)$ \\
\hline Cervical flexion & $260(57.9)$ & $5(1.1)$ & $7(1.6)$ & $177(39.4)$ & $65(54.6)$ & $2(1.7)$ & $3(2.5)$ & $49(41.2)$ & $195(59.1)$ & $3(0.9)$ & $4(1.2)$ & $128(38.8)$ \\
\hline \multicolumn{13}{|l|}{ Cervical rotation } \\
\hline Right & $186(41.4)$ & $2(0.4)$ & $5(1.1)$ & $256(57.0)$ & $43(36.1)$ & $1(0.8)$ & $2(1.7)$ & $73(61.3)$ & $143(43.3)$ & $1(0.3)$ & $3(0.9)$ & $183(55.5)$ \\
\hline Left & $158(35.2)$ & $2(0.4)$ & $6(1.3)$ & $283(63.0)$ & $38(31.9)$ & $1(0.8)$ & $2(1.7)$ & $78(65.5)$ & $120(36.4)$ & $1(0.3)$ & $4(1.2)$ & $205(62.1)$ \\
\hline \multicolumn{13}{|l|}{ ANY cervical rotation } \\
\hline Pain & \multirow{2}{*}{\multicolumn{4}{|c|}{$\begin{array}{c}8(1.8) \\
299(66.6)\end{array}$}} & $3(2.5)$ & & & & \multicolumn{4}{|c|}{$5(1.5)$} \\
\hline Dysfunction & & & & & $84(70.6)$ & & & & \multicolumn{4}{|c|}{$215(65.2)$} \\
\hline Forward bending & \multicolumn{4}{|c|}{$3(0.7) \quad 15(3.3)$} & $17(14.3)$ & $2(1.7)$ & $8(6.7)$ & $92(77.3)$ & $57(17.3)$ & $1(0.3)$ & $7(2.1)$ & $265(80.3)$ \\
\hline Overhead squat & $24(5.3)$ & $2(0.4)$ & $56(12.5)$ & $367(81.7)$ & $12(10.1)$ & 0 & $14(11.8)$ & $93(78.2)$ & $12(3.6)$ & $2(0.6)$ & $42(12.7)$ & $274(83.0)$ \\
\hline \multicolumn{13}{|l|}{ Single-leg stance } \\
\hline Right & $158(35.2)$ & $3(0.7)$ & $11(2.4)$ & $277(61.7)$ & $44(37.0)$ & $1(0.8)$ & 0 & $74(62.2)$ & $114(34.5)$ & $2(0.6)$ & $11(3.5)$ & $203(61.5)$ \\
\hline Left & $153(34.1)$ & $1(0.2)$ & $11(2.4)$ & $284(63.3)$ & $40(33.6)$ & 0 & $1(0.8)$ & $78(65.5)$ & $113(34.2)$ & $1(0.3)$ & $10(3.0)$ & $206(62.4)$ \\
\hline \multicolumn{13}{|l|}{ ANY single-leg stance } \\
\hline Pain & \multicolumn{4}{|c|}{$14(3.1)$} & $1(0.8)$ & & & & \multicolumn{4}{|c|}{$13(3.9)$} \\
\hline Dysfunction & \multicolumn{4}{|c|}{$354(78.8)$} & $92(77.3)$ & & & & \multicolumn{4}{|c|}{$262(79.4)$} \\
\hline \multicolumn{13}{|l|}{ Trunk rotation } \\
\hline Right & $82(18.3)$ & $3(0.7)$ & $18(4.0)$ & $346(77.1)$ & $22(18.5)$ & $2(1.7)$ & $7(5.9)$ & $88(73.9)$ & $60(18.2)$ & $1(0.3)$ & $11(3.3)$ & $258(78.2)$ \\
\hline Left & $101(22.5)$ & $1(0.2)$ & $21(4.7)$ & $326(72.6)$ & $23(19.3)$ & 0 & $10(8.4)$ & $86(72.3)$ & $78(23.6)$ & $1(0.3)$ & $11(3.3)$ & $240(72.7)$ \\
\hline \multicolumn{13}{|l|}{ Any trunk rotation } \\
\hline Pain & \multirow{2}{*}{\multicolumn{4}{|c|}{$\begin{aligned} 22 & (4.9) \\
381 & (84.9)\end{aligned}$}} & $10(8.4)$ & & & & \multicolumn{4}{|c|}{$12(3.6)$} \\
\hline Dysfunction & & & & & $102(85.7)$ & & & & & 279 & 84.5) & \\
\hline Upper-extremity pattern (LRF) & & & & & & & & & \\
\hline Right & $174(38.8)$ & $22(4.9)$ & $23(5.1)$ & $230(51.2)$ & $51(42.9)$ & $4(3.4)$ & $6(5.0)$ & $58(48.7)$ & $123(37.3)$ & $18(5.5)$ & $17(5.2)$ & $172(52.1)$ \\
\hline Left & $154(34.3)$ & $12(2.7)$ & $31(6.9)$ & $252(56.1)$ & $44(37.0)$ & $2(1.7)$ & $7(5.9)$ & $66(55.5)$ & $110(33.3)$ & $10(3.0)$ & $24(7.3)$ & $186(56.4)$ \\
\hline Any upper-extremity pattern (LRF) & & & & & & & & & & & & \\
\hline Pain & & 47 & 10.5) & & & & $(9.2)$ & & & 36 & 10.9) & \\
\hline Dysfunction & & 300 & $(66.8)$ & & & & $(66.4)$ & & & 221 & 67.0) & \\
\hline Upper-extremity pattern (MRE) & & & & & & & & & & & & \\
\hline Right & $150(33.4)$ & $7(1.6)$ & $32(7.1)$ & $260(57.9)$ & $38(31.9)$ & $2(1.7)$ & $4(3.4)$ & $75(63.0)$ & $112(33.9)$ & $5(1.5)$ & $28(8.5)$ & $185(56.1)$ \\
\hline Left & $189(42.1)$ & $10(2.2)$ & $28(6.2)$ & $222(49.4)$ & $51(42.9)$ & $2(1.7)$ & $4(3.4)$ & $62(52.1)$ & $138(41.8)$ & $8(2.4)$ & $24(7.3)$ & $160(48.5)$ \\
\hline Any-upper extremity pattern (MRE) & & & & & & & & & & & & \\
\hline Pain & & & (8.9) & & & & (5.0) & & & 34 & 10.3) & \\
\hline Dysfunction & & 317 & (70.6) & & & & (72.3) & & & 231 & 70.0) & \\
\hline Asymmetry & & & & & & & & & & & & \\
\hline Cervical rotation & & 114 & (25.4) & & & & (25.2) & & & 84 & 25.5) & \\
\hline Single-leg stance & & 193 & (43.0) & & & & (44.5) & & & 140 & 42.4) & \\
\hline Trunk rotation & & 215 & (47.9) & & & & (51.3) & & & 154 & 46.7) & \\
\hline Upper-extremity pattern 1 (LRF) & & 84 & 18.7) & & & & (22.7) & & & 57 & 17.3) & \\
\hline Upper-extremity pattern 2 (MRE) & & 154 & (34.3) & & & & (33.6) & & & 114 & 34.5) & \\
\hline
\end{tabular}


Perceived Readiness

Soldiers also answered a question about their perceived ability to pass their biannual physical fitness test (yes or no) and whether in their opinion they felt they needed any more medical care before returning to duty. They were also asked to provide a score from 0 to $100 \%$ for the question "based on my specific military occupational specialty, taking into consideration my current and foreseeable position, I think I am mission capable."

\section{Statistical Analysis}

We calculated frequency counts for scores (1-4) of each of the SFMA-TTM movement patterns at baseline, and subgroups by recent injury category (lower-extremity or thoracic/lumbar spine). We also calculated the proportion of individuals at baseline that had any type of poor-quality movement (regardless of pain) and any pain with movement (regardless of quality). To determine the relationship between presence of dysfunction and pain with baseline SFMA-TTM tests and injury occurrence, we ran $2 \times 2$ and $2 \times 4$ contingency tables using injury (yes or no) and dysfunctional movement patterns (1-4), any painful pattern (regardless of dysfunction) and any dysfunctional pattern (regardless of pain). We also assessed the relationship between the presence of pain or dysfunction in one region with SFMA-TTM testing (lower extremity or trunk) and the location of the subsequent time-loss injury (lower extremity or thoracic/lumbar spine). Results were reported for the entire cohort, and then also by original injury region subgroup (lumbar/thoracic spine vs lower extremity).

\section{Results}

The study enrolled 480 participants and after exclusions for various reasons (Fig 1), data for a final cohort of 449 soldiers ( 65 female; mean age 27.2 years) were analyzed. Demographic variables were similar between patients with recent thoracic/lumbar spine and lowerextremity injuries, except for a slightly larger proportion of smokers in the thoracic/lumbar spine group (Table 1). Upon being cleared to return to unrestricted full duty, regardless of recent injury type, $99.8 \%$ presented with at least 1 dysfunctional movement pattern, and $37.0 \%(\mathrm{~N}=166)$ had dysfunction with 9 of the 10 movement patterns (Table 2). Nearly one-half $(44.1 \%)$ had pain with at least 1 of the movements $(40.3 \%$ with previous lower-extremity injury; $54.6 \%$ with previous spine injury), and $79.5 \%$ demonstrated asymmetry with movement from side to side $(78.8 \%$ with previous lower-extremity injury; $81.5 \%$ with previous spine injury; range of asymmetry from $18.7 \%$ to $47.9 \%$ depending on the movement; Fig 2). The 2 most common painful movements were back bending $(\mathrm{n}=125$; $27.8 \%)$ and overhead squat $(\mathrm{n}=58 ; 12.9 \%)$. The 2 


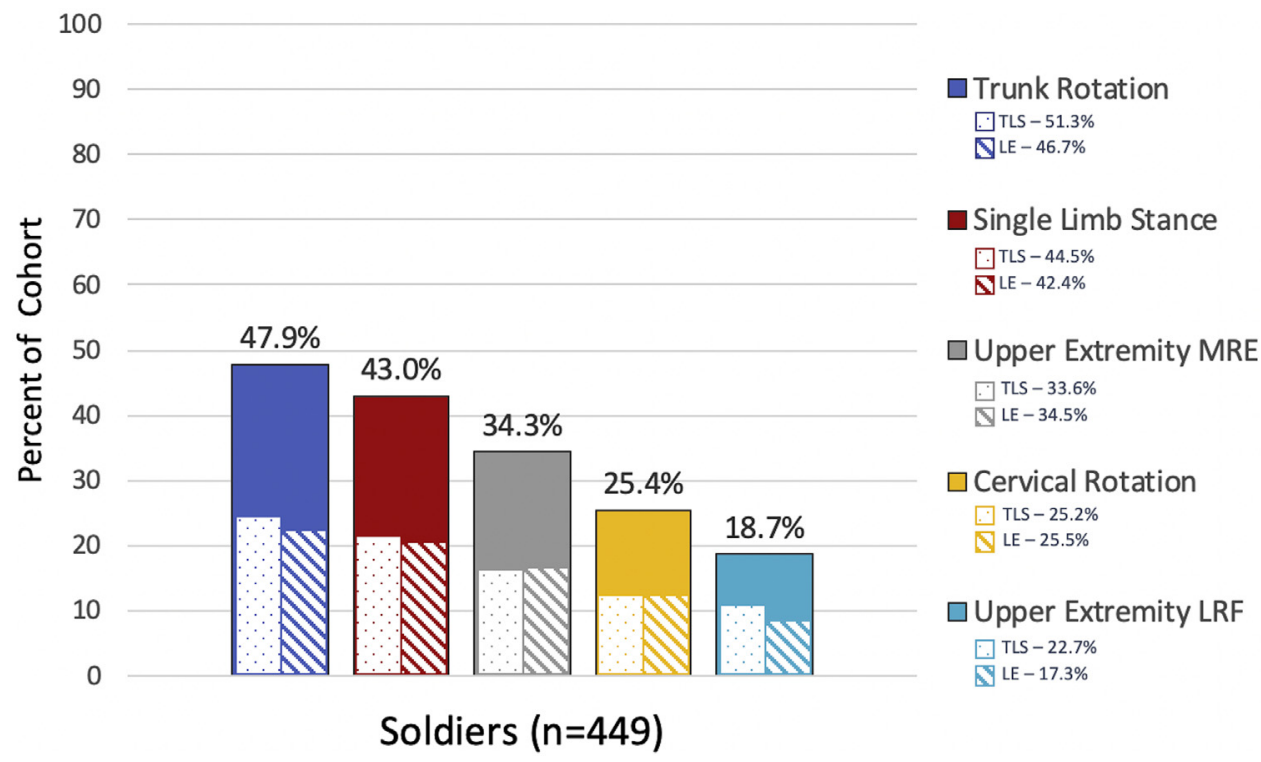

Fig 2. Proportion of individuals with asymmetry on each bilateral SFMA movement. (MRE, medial rotation and extension; LE, lower extremity; LRF, lateral rotation and flexion; TLS, time loss injury.) most common dysfunctional movements were overhead squat $(\mathrm{n}=423,94.2 \%$ overall; $95.8 \%$ with previous lower-extremity injury; $89.9 \%$ with previous spine injury\%) and trunk rotation ( $\mathrm{n}=381,84.9 \%$ overall; $84.5 \%$ with previous lower-extremity injury; $85.7 \%$ with previous spine injury). When assessing SFMA-TTM patterns based on body region of the recent injury, as expected, a greater proportion of those with recent thoracolumbar spine injuries presented with painful spine and trunk movements on the SFMA-TTM, and a greater proportion of those with a recent lowerextremity injury presented with pain during lowerextremity movements on the SFMA-TTM (Table 2).

The frequency of pain was significantly greater with movement patterns for back bending $(38.7 \%$ vs $23.9 \%)$, forward bending $(8.4 \%$ vs $2.4 \%)$, and trunk rotation $(8.4 \%$ vs $3.6 \%)$ in those with recent spine injuries versus lower-extremity injuries, respectively. Slightly more soldiers with previous thoracolumbar injuries also presented with a dysfunction classification while back bending ( $87.4 \%$ vs $77.3 \%)$, whereas slightly more soldiers with lower-extremity injuries presented with dysfunction classification during the overhead squat $(95.8 \%$ vs $89.9 \%)$. Also at discharge, 1 in 10 ( $10.7 \%$ overall; $10.6 \%$ with previous lower-extremity injury, $10.9 \%$ with previous spine injury) felt they could not pass their required physical fitness test at the time of discharge, and $16.1 \%$ (16.1\% lower-extremity; $16.0 \%$ spine) agreed that they should have received more medical care before being cleared to return to duty. Only 334 (74.4\% overall; $73.6 \%$ with previous lower-extremity injury, $76.5 \%$ with previous spine injury) felt that they were $100 \%$ mission capable at this time.
Of the 449 participants, 170 (37.9\% overall; $37.3 \%$ with original lower-extremity injury, $39.5 \%$ with original spine injury) sustained a time-loss injury during the 1-year follow-up period (Table 3). Dysfunctional nonpainful movement was the most common baseline finding in 9 of the 10 movement patterns for soldiers that sustained a new injury (Fig 3). Dysfunctional movement identified when soldiers were cleared to return to duty from a previous injury was present in 170 individuals $(37.9 \%)$ that eventually sustained a future time loss injury and also present in 278 individuals $(61.9 \%)$ who did not go on to sustain a follow-on injury. Pain with movement during baseline SFMA-TTM testing was associated with future injury, present in $50.6 \%$ of individuals who sustained a time loss injury compared with only $40.1 \%$ of individuals without an injury (odds ratio [OR] 1.53, 95\% confidence interval $[\mathrm{CI}]$ 1.04-2.24; $P=.032$ ). Pain with movement was not significantly different for any of the 10 individual movements between those who sustained a follow-on injury and those who did not (Table 4). The most common painful movement in those that sustained a follow-on injury was multisegmental trunk extension (Fig 3). Within subgroups of previous injuries, dysfunction with forward bending was significantly associated with future injury only in the soldiers with a recent thoracic/lumbar spine injury (OR 4.19, 95CI 1.15-15.30; $P=.023$ ). In soldiers with a recent lower-extremity injury at time of enrollment who then sustained another lower-extremity injury during the 1year surveillance period, $96(50.0 \%)$ had pain with at least one SFMA-TTM movement. Having pain in the lower-extremity with SFMA-TTM testing (single leg stance and/or overhead squat) increased the odds of 
Table 3. Injury Occurrence Categories During 1-Year Follow-Up Period

\begin{tabular}{|c|c|c|c|c|c|}
\hline \multirow[b]{3}{*}{ Previous Injury $(\mathrm{N}=449)$} & \multicolumn{5}{|c|}{ Future Injury (Sustained During Follow-Up Period) } \\
\hline & \multicolumn{2}{|c|}{ Lumbar or Thoracic Spine } & \multicolumn{2}{|c|}{ Lower Extremity } & \multirow{2}{*}{$\begin{array}{c}\text { Other } \\
\text { Time Loss }\end{array}$} \\
\hline & Time Loss & Health Seeking & Time Loss & Health Seeking & \\
\hline Lower extremity $(\mathrm{n}=330)$ & $21(6.4)$ & $69(20.9)$ & $96(29.1)$ & $322(97.6)$ & $25(7.6)$ \\
\hline
\end{tabular}

NOTE. Values represent total number and proportion (\%) of soldiers in each category.

sustaining a future time loss lower-extremity injury (OR 1.76, 95\% CI 1.01-3.06; $P=.044$ ). This same relationship was not seen when patients had pain with movement of the trunk (back bending, forward bending and/or rotation) and an associated spine injury.

\section{Discussion}

These findings highlight that 1 in 4 soldiers did not feel like they were $100 \%$ mission capable upon returning to full duty. This study also identified a high proportion of soldiers who were returned to full duty from a recent injury still having pain with functional movements $(44.1 \%$ overall; $40.3 \%$ with previous lower-extremity injury and $54.6 \%$ with previous spine injury) and patterns of movement considered dysfunctional according to the SFMA (99.8\%). Pain with movement on at least 1 of the 10 SFMA-TTM movement patterns was significantly associated with a future injury. These findings are significant considering that upon return to unrestricted duty following recovery from an injury, soldiers are expected to be ready to complete regular physical training, fitness testing, and adequately meet the physical demands of their military occupational specialty. ${ }^{18}$

Pain with movement present in nearly one-half of these soldiers $(44.1 \%)$ when cleared to return to duty is noteworthy. Because pain with movement is an important risk factor for future injury, ${ }^{6,7,19}$ it should receive attention when considering the appropriateness for returning to work and physical activity after injury. Even if a future injury is not incurred, it is likely that individuals who have pain with movement are not operating as efficiently as they could without pain. In settings that demand high levels of physical activity, such as the military, painful movement will likely result in substantial work-related limitations and diminished patient well-being. Reducing painful movement not only mitigates risk of future injury but also has the potential to optimize individual performance upon returning to full duty. Rehabilitation providers should examine whether they are systematically assessing the presence of pain with movement patterns and determine how they might mitigate this risk factor. ${ }^{20}$ Rehabilitation programs can be designed with an endgoal of pain-free movement.
The primary purpose of the SFMA-TTM is to identify painful patterns of movement and movement impairments associated with the patient's primary reason for seeking injury-related care to manage regional interdependence and provide a target for treatment. The validity of the SFMA-TTM as a tool to predict clinical outcomes has been investigated previously. In collegiate baseball players, poor performance on the SFMATTM upper extremity movement tests (any pain or dysfunctional movement) was associated with symptoms of overuse (pain, soreness, fatigue) during the preseason and regular season. ${ }^{21}$ Riebel et al. ${ }^{17}$ assessed changes in SFMA-TTM from baseline to discharge from physical therapy for an injury and the correlation between these changes and changes in self-reported measures of pain and function seen over the same period of time. Fair-to-good association was seen between improvements in self-reported outcomes and reduction in pain with SFMA-TTM. However, the quality of the movement was not associated with improvements in self-reported outcomes. ${ }^{17}$ This aligns with the findings from our study, showing a significant relationship between future injury and pain with SFMA-TTM but not with dysfunctional movements that were not painful. Future research is needed to validate these claims, but this study suggests that the SFMA alone may not be the best prognostic tool to determine future injury risk. However, as primarily a clinical framework tool, its focus is to guide the clinician in addressing relevant impairments that affect individual performance, rather than predict injury. Even if an injury is not realized, performance can suffer when an individual is not moving well or has pain with movement. $^{22}$

The association between quality of movement and function has been debated and merits further discussion considering almost every single individual in this cohort had at least one dysfunctional movement. Intuitively, and probably at the macro level, a normal range of kinematics is associated with improved performance (e.g., greater muscle activation, efficient transfer of energy through the kinetic chain). ${ }^{8,9,23}$ Optimal biomechanical movement in theory reduces the risk for injury by improving the efficiency by which the body absorbs load and reacts to external forces. ${ }^{24}$ However, there are many examples of individuals with high levels of function despite poor movement quality. The ability 


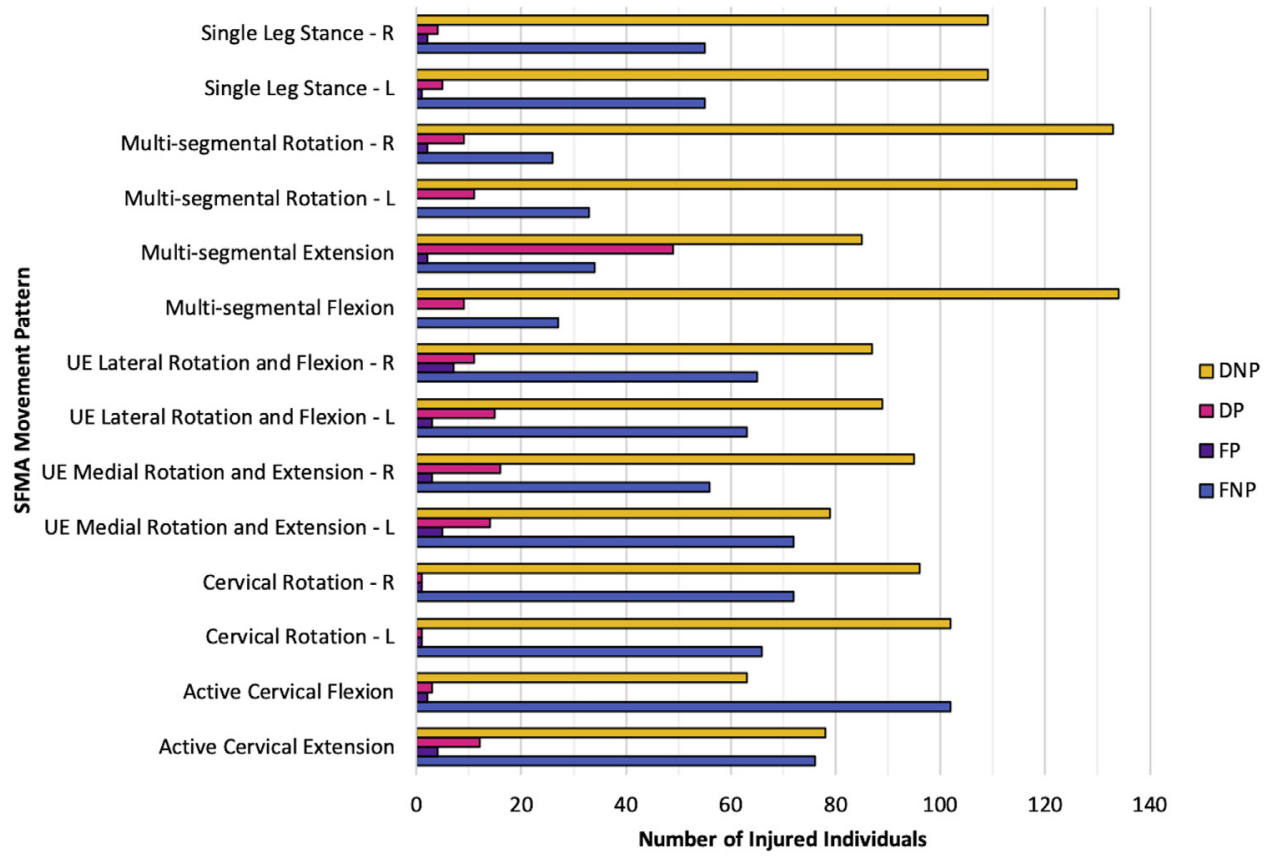

Fig 3. Frequency of categorical SFMA ratings for individuals with a time Loss $(\mathrm{n}=170)$. (DNP, dysfunctional nonpainful; DP, dysfunctional painful; FNP, functional nonpainful; FP, functional painful; L, left; R, right; UE, upper extremity.) to compensate for poor movement can be variable, allowing some individuals to adapt better than others to suboptimal movement patterns and lower their risk of injury. Therefore, even though movement is poor, it may not always lead to greater risk of injury in those that can properly adapt. To further complicate this debate, there is conflicting evidence in many cases about the role that some biomechanical factors play in select injuries. ${ }^{25-27}$ Others have argued that the assessment of movement as a valid predictor of injury is often subject to confounding, limiting its value. For example, there is no consensus on the definition of "normal movement" in many cases. ${ }^{28}$ As few as $27 \%$ of subjects in a normative cohort were considered to use "true normative movement patterns." ${ }^{29}$ It is often difficult to assess the role that pain, fatigue, and psychological profile can play in the performance of these movement assessments. ${ }^{29}$ However, the association between SFMA-TTM scores and performance on military-relevant events (e.g., mandatory biannual physical fitness test) has not been formally assessed. Clinical identification of physical impairments that underpin dysfunctional movement, rather than identification of future injury risk, is the hallmark of the SFMA.

Previous injury is one of the strongest predictors of future injury (recurrence or new injury) in both military and civilian settings. ${ }^{5,6,30-34}$ In this cohort, every individual participating in this study had this risk factor, highlighting the importance of identifying other known risk factors to help protect the patient from another injury. While SFMA-TTM results could be different in a nonclinical population, this is the setting the assessment tool was designed for. It is possible that a measure of past injury severity could strengthen the relationship between performance on the SFMA-TTM and performance with military-specific physical tasks when returning from duty or occurrence of future injury. The association between SFMA-TTM and future militaryspecific physical tasks was not assessed in our cohort. One previous study found that collegiate baseball players with a history of surgery to the elbow or shoulder did not perform any differently on the SFMATTM than players without this history. ${ }^{35}$ In our cohort, there was a significant association between the location of the recent injury, the location of pain with SFMATTM testing, and the location of future injuries. Soldiers with a recent lower-extremity injury and pain with SFMA-TTM tests that involved movement of the lower-extremity were more likely to sustain a subsequent lower-extremity injury. This relationship should be explored further.

Clinicians and rehabilitation professionals need better guidance to optimize returning soldiers back to full unrestricted duty. Performance likely needs to play a key role in the decisions, given the physical demands that are inherent with military service. A variety of tests, when used in isolation, appear to alone be subpar predictors of injury risk. The likely reason for this is the often complex and multifactorial nature of injuries. ${ }^{36,37}$ Prediction models often create a dichotomous outcome of injury (yes or no), but the actual injury event is more nuanced. Beyond the injury event alone, recovery from the same injury type can be highly variable and 
Table 4. Association Between Pain and Dysfunction With SFMA Movement Testing

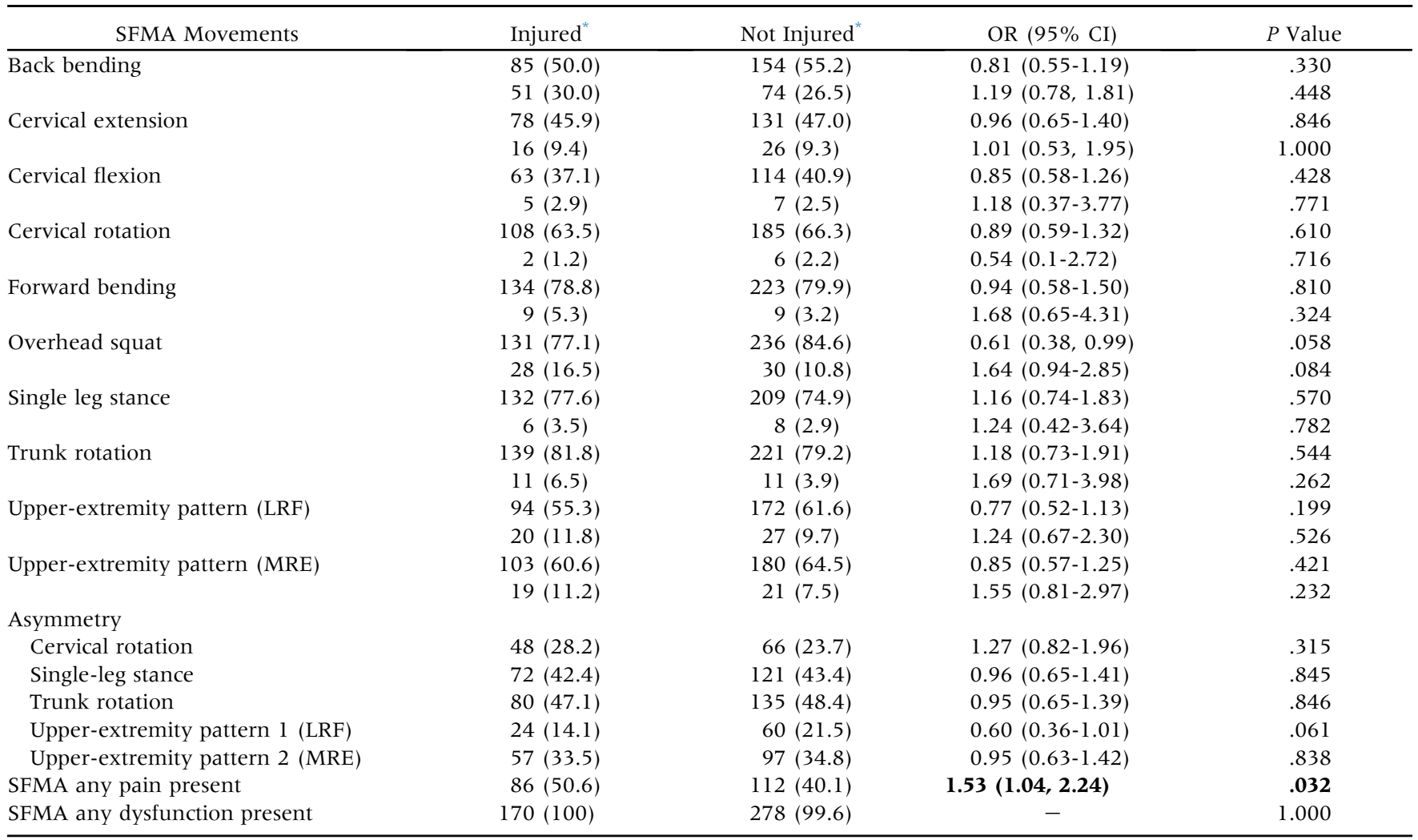

NOTE. First value represents individuals with a dysfunctional pattern and no pain; second value represents individuals with painful movement (with or without dysfunction). All values represent $\mathrm{n}$ (\% within group). Bold values represent significance at the $P<.05$ level.

$\mathrm{CI}$, confidence interval; LRF, lateral rotation and flexion; MRE, medial rotation and extension; OR, odds ratio; SFMA, Selective Functional Movement Assessment.

*Future injury status after being cleared to return to fully duty.

influenced by many other factors beyond the purely physiological healing process alone. ${ }^{38,39}$ Due to this complexity, it's unlikely that a single predictor variable alone will be enough to successfully identify individuals at risk for injury and accurately discriminate from individuals that will not be injured. This may explain why other functional movement tests alone have fallen short of this goal in the past. ${ }^{40}$ However, these tests when used as part of a comprehensive battery of injuryrelated information (e.g., movement, balance, range of motion, medical history) have resulted in robust significant algorithms to help prevent injury risk in athlete and military populations. ${ }^{7,19,41,42}$ In addition, future injury is not the only important metric, but also how well someone performs when they return to duty.

\section{Limitations}

This study comes with several limitations. Training and deployment cycles are highly variable and less predictable than in athlete populations, and therefore the timing of these events amongst military units could influence injury rates but was not tracked for this study. Female subjects were represented proportionally to those found in these military units; however, their numbers were still too low to allow for meaningful subgroup analysis. Female sex has been shown to be a significant risk factor for injury in the military. ${ }^{1,6}$ This study also highlights the importance of using time loss injuries rather than health seeking alone, considering almost the entire cohort sought medical care in the 1year follow-up. Many of these visits could have been periodic check-ins to review or progress their selfmanagement plan, with no requirement for missing time from duty. A better proxy for injury could exist and may result in stronger relationships between these variables (e.g., severity of injury, classifying injuries as acute or overuse, total number of duty days lost). The functional movements assessed in the SFMA-TTM may not be the best to reflect movements in soldiers that are associated with future injury, and it is possible other movements, such as those during dynamic balance testing, could have provided better discrimination. Finally, this study occurred in the U.S. Army, and it is unknown if the findings would be similar in other services (e.g., Navy, Air Force, Marines) or other countries. 


\section{Conclusions}

One in 4 patients did not feel $100 \%$ mission capable upon being cleared for full duty. Pain with movement also was associated with future injury. Regardless of recent injury type, $99.8 \%$ of soldiers returned to full unrestricted duty with at least 1 dysfunctional movement pattern, and $44.1 \%$ had pain with at least 1 of the SFMA-TTM movements.

\section{References}

1. Molloy JM, Pendergrass TL, Lee IE, Chervak MC, Hauret KG, Rhon DI. Musculoskeletal injuries and United States Army Readiness Part I: Overview of injuries and their strategic impact. Mil Med 2020;185:e1461-el471.

2. DoD Health of the Force 2020. Army Public Health Center; 2021, https://phc.amedd.army.mil/PHC \%20Resource \%20 Library/2020-hof-web.pdf. Accessed June 6, 2021.

3. Roy TC, Faller TN, Richardson MD, Taylor KM. Characterization of limited duty neuromusculoskeletal injuries and return to duty times in the U.S. Army During 20172018 [Published online January 9, 2021]. Mil Med, https:// doi.org/10.1093/milmed/usaa392.

4. Military Health System Communication Office. DHA priorities focused on readiness, patients, outcomes, https://health. mil/News/Articles/2020/10/07/DHA-priorities-focused-onreadiness-patients-outcomes. Published October 7, 2020. Accessed July 18, 2021.

5. Toohey LA, Drew MK, Cook JL, Finch CF, Gaida JE. Is subsequent lower limb injury associated with previous injury? A systematic review and meta-analysis. Br J Sports Med 2017;51:1670-1678.

6. Rhon DI, Molloy JM, Monnier A, Hando BR, Newman PM. Much work remains to reach consensus on musculoskeletal injury risk in military service members: A systematic review with meta-analysis [Published online June 18, 2021.]. EJSS, https://doi.org/10.1080/17461391. 2021.1931464.

7. Teyhen DS, Shaffer SW, Goffar SL, et al. Identification of risk factors prospectively associated with musculoskeletal injury in a warrior athlete population. Sports Health 2020;12:564-572.

8. Markström JL, Grip H, Schelin L, Häger CK. Dynamic knee control and movement strategies in athletes and non-athletes in side hops: Implications for knee injury. Scand J Med Sci Sports 2019;29:1181-1189.

9. Karandikar N, Vargas OOO. Kinetic chains: A review of the concept and its clinical applications. PM R 2011;3:739-745.

10. Davies WT, Myer GD, Read PJ. Is it time we better understood the tests we are using for return to sport decision making following ACL reconstruction? A critical review of the hop tests. Sports Med 2020;50:485-495.

11. Glaws KR, Juneau CM, Becker LC, Di Stasi SL, Hewett TE. Intra- and inter-rater reliability of the selective functional movement assessment (SFMA). Int J Sports Phys Ther 2014;9:195-207.

12. Goshtigian GR, Swanson BT. Using the selective functional movement assessment and regional interdependence theory to guide treatment of an athlete with back pain: A case report. Int J Sports Phys Ther 2016;11: 575-595.

13. Stanek JM, Smith J, Petrie J. Intra- and inter-rater reliability of the selective functional movement assessment (SFMA) in healthy participants. Int J Sports Phys Ther 2019;14:107-116.

14. Dolbeer J, Mason J, Morris J, Crowell M, Goss D. Interrater reliability of the selective functional movement assessment (SFMA) by SFMA-certified physical therapists with similar clinical and rating experience. Int J Sports Phys Ther 2017;12:752-763.

15. McCrum C, Bryant E, Murtagh S, et al. Patients' expectations of physiotherapy treatment for musculoskeletal conditions. Physiotherapy 2016;102:e22-e23.

16. Rhon DI, Teyhen DS, Shaffer SW, Goffar SL, Kiesel K, Plisky PP. Developing predictive models for return to work using the Military Power, Performance and Prevention (MP3) musculoskeletal injury risk algorithm: A study protocol for an injury risk assessment programme. Inj Prev 2018;24:81-88.

17. Riebel M, Crowell M, Dolbeer J, Szymanek E, Goss D. Correlation of self-reported outcome measures and the selective functional movement assessment (SFMA): An exploration of validity. Int J Sports Phys Ther 2017;12: 931-947.

18. Office of The Surgeon General. Army Regulation 40-502: Medical Readiness. Headquarters Department of the Army; 2019, https://armypubs.army.mil/epubs/DR_pub s/DR_a/pdf/web/ARN8680_AR40_502_FINAL_WEB.pdf. Accessed June 27, 2019.

19. Teyhen DS, Shaffer SW, Butler RJ, et al. What risk factors are associated with musculoskeletal injury in US Army Rangers? A prospective prognostic study. Clin Orthop Relat Res 2015:473:2948-2958.

20. Butera KA, Fox EJ, George SZ. Toward a transformed understanding: From pain and movement to pain with movement. Phys Ther 2016;96:1503-1507.

21. Busch AM, Clifton DR, Onate JA, Ramsey VK, Cromartie F. Relationship of preseason movement screens with overuse symptoms in collegiate baseball players. Int $J$ Sports Phys Ther 2017;12:960-966.

22. Teyhen DS, Rhon DI, Butler RJ, et al. Association of physical inactivity, weight, smoking, and prior injury on physical performance in a military setting. J Athl Train 2016;51:866-875.

23. Deal MJ, Richey BP, Pumilia CA, et al. Regional interdependence and the role of the lower body in elbow injury in baseball players: A systematic review. Am J Sports Med 2020;48:3652-3660.

24. Hewett TE, Bates NA. Preventive biomechanics: A paradigm shift with a translational approach to injury prevention. Am J Sports Med 2017;45:2654-2664.

25. Cronström A, Creaby MW, Ageberg E. Do knee abduction kinematics and kinetics predict future anterior cruciate ligament injury risk? A systematic review and metaanalysis of prospective studies. BMC Musculoskelet Disord 2020;21:563.

26. Krosshaug T, Steffen K, Kristianslund E, et al. The vertical drop jump is a poor screening test for ACL injuries in female elite soccer and handball players: A prospective 
cohort study of 710 athletes. Am J Sports Med 2016;44: 874-883.

27. Hewett TE, Myer GD, Ford KR, et al. Biomechanical measures of neuromuscular control and valgus loading of the knee predict anterior cruciate ligament injury risk in female athletes: A prospective study. Am J Sports Med 2005;33:492-501.

28. Bahr R. Why screening tests to predict injury do not work-and probably never will...: A critical review. Br J Sports Med 2016;50:776-780.

29. Richter C, King E, Strike S, Franklyn-Miller A. Objective classification and scoring of movement deficiencies in patients with anterior cruciate ligament reconstruction. PLoS One 2019;14:e0206024.

30. Jones BH, Thacker SB, Gilchrist J, Kimsey CD Jr, Sosin DM. Prevention of lower extremity stress fractures in athletes and soldiers: A systematic review. Epidemiol Rev 2002;24:228-247.

31. Wilkinson DM, Blacker SD, Richmond VL, et al. Injuries and injury risk factors among British army infantry soldiers during predeployment training. Inj Prev 201 1;17:381-387.

32. Murphy DF, Connolly DAJ, Beynnon BD. Risk factors for lower extremity injury: A review of the literature. $\mathrm{Br} J$ Sports Med 2003;37:13-29.

33. Maffey L, Emery C. What are the risk factors for groin strain injury in sport? A systematic review of the literature. Sports Med 2007;37:881-894.

34. Seay JF, Shing T, Wilburn K, Westrick R, Kardouni JR. Lower-extremity injury increases risk of first-time low back pain in the US Army. Med Sci Sports Exerc 2018;50: 987-994.
35. Busch AM, Clifton DR, Onate JA. Relationship of movement screens with past shoulder or elbow surgeries in collegiate baseball players. Int J Sports Phys Ther 2018;13: 1008-1014.

36. Bittencourt NFN, Meeuwisse WH, Mendonça LD, NettelAguirre A, Ocarino JM, Fonseca ST. Complex systems approach for sports injuries: Moving from risk factor identification to injury pattern recognition-narrative review and new concept. Br J Sports Med 2016;50: 1309-1314.

37. Fonseca ST, Souza TR, Verhagen E, et al. Sports injury forecasting and complexity: A synergetic approach. Sports Med 2020;50:1757-1770.

38. Hsu C-J, Meierbachtol A, George SZ, Chmielewski TL. Fear of reinjury in athletes. Sports Health 2017;9:162-167.

39. Lentz TA, Paterno MV, Riboh JC. So you think you can return to sport? $\mathrm{Br}$ J Sports Med 2018;52:14821483.

40. Moran RW, Schneiders AG, Mason J, Sullivan SJ. Do Functional Movement Screen (FMS) composite scores predict subsequent injury? A systematic review with meta-analysis. Br J Sports Med 2017;51:1661-1669.

41. Lehr ME, Cheek W, Dacko S, et al. Movement patterns and neuromusculoskeletal impairments observed in a female Olympic field hockey team: An observational cohort study. J Bodyw Mov Ther 2021;26:128-133.

42. Lehr ME, Plisky PJ, Butler RJ, Fink ML, Kiesel KB, Underwood FB. Field-expedient screening and injury risk algorithm categories as predictors of noncontact lower extremity injury. Scand J Med Sci Sports 2013;23: e225-e232. 